\title{
Long-term functional results of transvaginal anal sphincter repair for faecal incontinence; a retrospective cohort study.
}

\author{
Frida Carswell ${ }^{1}$, Peter Dwyer ${ }^{1}$, Ariel Zilberlicht ${ }^{2}$, James Alexander ${ }^{3}$, Madhu Bhamidipaty ${ }^{4}$, \\ Alison De Souza ${ }^{1}$, Alex Wong ${ }^{5}$, James Keck ${ }^{4}$, and Lore Schierlitz ${ }^{1}$ \\ ${ }^{1}$ Mercy Hospital for Women \\ ${ }^{2}$ Carmel Medical Center \\ ${ }^{3}$ The Royal Hospital for Women \\ ${ }^{4}$ St Vincent Hospital \\ ${ }^{5}$ Box Hill Hospital
}

October 18, 2021

\begin{abstract}
Objective We report our experience with a transvaginal approach with overlapping AS repair. The aim of this study was to evaluate long term functional outcomes. Design Retrospective Cohort study. Setting and Population Women who had undergone AS surgery for anal incontinence from July 2005 to July 2020. were included. The patients included attended the Mercy Hospital Perineal clinic a multidisciplinary team of urogynecologists and colorectal surgeons. Private patients from the surgeons in Perineal clinic were also included. Methods Overall 107 women were included in the study with a median follow up of 57.5 months. Main Outcome Measure We analysed outcomes by comparing patients St marks score difference before and after surgery. Meaningful clinical difference (MID) was set at 5 points as per previous validation studies, complications and patient demographics were recorded along with a question if they would recommend this treatment to a friend. Results An improvement exceeding the minimal clinical difference (MID) was seen in $69.3 \%$ of women. With a marked improvement in $46.5 \%$ of patients. Furthermore $70 \%$ of our patients would recommend the procedure to a friend, if they were in a similar situation. Wound infection or perineal breakdown occurred in $45 \%$ of women but did not significantly impact on outcomes. Conclusion Transvaginal AS repair is associated with significant improvements in patients' St. Marks score. Our data shows that the long-term success rate of transvaginal AS repair may be better than previously reported in the literature using a transvaginal approach. Funding This study received no funding or sponsorship
\end{abstract}

Long-term functional results of transvaginal anal sphincter repair for faecal incontinence; a retrospective cohort study.

Dr Frida Carswell, Urogynaecology Department, Mercy Hospital for Women, VIC, Australia, fridacarswell@gmail.com ph0384584444

Prof Peter Dwyer, Urogynaecology Department, Mercy Hospital for Women, peter@plddwyer.com, ph 039416 2469

Dr Ariel Zilberlicht The Lady Davis Carmel medical Centre, Haifa, Israel. arielzilberlicht@gmail.com ,ph +972522904352

Dr James Alexander, Urogynaecology department, Mercy Hospital for Women, Jwood.alexander@gmail.com ph 0384584444

Dr Madhu Bhamidipaty, Department of Surgery St Vincent's Hospital Melbourne. m.bhamidipaty@gmail.com,ph 0392312211 
Dr Alison Desousa, Urogynaecology department Mercy Hospital for Women, adesouza@bigpond.net.au ph 0394199699

Dr Jamie Keck, Department of Surgery, Eastern Health, Box Hill, VIC, James.KECK@svha.org.au ph 0394193377

Dr Alex Wong, Department of Surgery, Eastern Health, Box Hill, VIC, awch@yahoo.com ph 1300858405

Dr Lore Schierlitz Urogynaecology Department, Mercy Hospital for Women, lsc54031@bigpond.net.au ph 0384584444

\section{Abstract}

\section{Objective}

We report our experience with a transvaginal approach with overlapping AS repair. The aim of this study was to evaluate long term functional outcomes.

\section{Design}

Retrospective Cohort study.

\section{Setting and Population}

Women who had undergone AS surgery for anal incontinence from July 2005 to July 2020. were included. The patients included attended the Mercy Hospital Perineal clinic a multidisciplinary team of urogynecologists and colorectal surgeons. Private patients from the surgeons in Perineal clinic were also included.

\section{Methods}

Overall 107 women were included in the study with a median follow up of 57.5 months.

\section{Main Outcome Measure}

We analysed outcomes by comparing patients St marks score difference before and after surgery. Meaningful clinical difference (MID) was set at 5 points as per previous validation studies, complications and patient demographics were recorded along with a question if they would recommend this treatment to a friend.

\section{Results}

An improvement exceeding the minimal clinical difference (MID) was seen in $69.3 \%$ of women. With a marked improvement in $46.5 \%$ of patients. Furthermore $70 \%$ of our patients would recommend the procedure to a friend, if they were in a similar situation. Wound infection or perineal breakdown occurred in $45 \%$ of women but did not significantly impact on outcomes.

\section{Conclusion}

Transvaginal AS repair is associated with significant improvements in patients' St. Marks score. Our data shows that the long-term success rate of transvaginal AS repair may be better than previously reported in the literature using a transvaginal approach.

\section{Funding}

This study received no funding or sponsorship

\section{Tweetable Abstract}

In a cohort of 88 women following transvaginal AS repair for AI, $69.3 \%$ had an improvement exceeding MID at 57 months.

\section{Introduction}


Anal incontinence (AI) is a very distressing condition that occurs in up to $15 \%$ of women (1) However the true incidence is likely to be higher as only a third of women with incontinence ever report this to their physician (2). Disruption of the anal sphincter caused by obstetric injury (Obstetric anal sphincter injury (OASI)), or anorectal operations are the most common causes of AI (3). It is estimated that $51 \%$ of patients reported some degree of AI following OASI (4). Third-degree tears occur during 2-6\% of vaginal deliveries and are usually repaired by obstetrician-gynaecologists, but "occult" sphincter injury that are unrecognized at delivery may occur in up to one-third of deliveries (5). AI following childbirth may result from sphincter damage or nerve injury, or both (6).

The most common finding is a defect in the anterior external anal sphincter, which often manifests clinically as urgency of defecation and faecal urge incontinence. Associated disruption of the internal sphincter may cause additional symptoms of passive or stress AI (7).

Conservative therapies (stool bulking agents, antidiarrheals and pelvic floor exercises/biofeedback) are the mainstay of initial treatment, with reported improvement of up to $80 \%$ (8). When conservative treatment fails, a sphincteroplasty or sacral nerve stimulation are commonly offered. Most reports on AS repair for faecal incontinence in the literature are uncontrolled case series mostly using the trans-perineal approach. There are very few studies comparing sphincteroplasty with other treatments.

Short term success rates for anal sphincter repair are up to $80 \%$. This reduces to $50 \%$ when patients were followed up for more than 5 years in a systematic review (1). In asymptomatic females, aging is associated with reduced anal resting and squeeze pressures, reduced rectal compliance, reduced rectal sensation, and perineal laxity (9).

Although AI deteriorates over the long-term following anal sphincteroplasty, patient QOL and satisfaction with improved control remain relatively high (1).

Prognostic factors associated with less favourable outcomes include advanced patient age, longer duration of incontinence and postoperative wound infection (10).

Over recent years there has been a number of changes and improvements, particularly in diagnostic techniques using ultrasound imaging of the AS. There has also been an introduction of other novel treatments such as Sacral Neuromodulation and Anal Bulking which have led to a decline in this procedure partly due to its poor long-term results in the current literature.

The objective of our study was to examine the long-term functional outcomes following transvaginal anal sphincter repair for faecal incontinence.

\section{Methods}

The study was a retrospective cohort study including women who had undergone a transvaginal anal sphincter repair surgery for AI from 1/7/2005-1/7/2020 at a dedicated perineal clinic in a tertiary urogynaecology centre with involvement of consultant urogynecologists and colorectal surgeons.

The study was approved by the local IRB committee. There was no sponsorship or funding awarded to this study.

\section{Patient selection}

Women with anal incontinence unresponsive to conservative treatment with a history of OASI or unrecognized/occult OASI as evident by endoanal ultrasound were included in the study if they underwent a transvaginal AS repair from July 2005 to July 2020. Women with concurrent rectovaginal fistula and AS repair were excluded from the main results and analysed as a separate group. Patients with inadequate data, and those who failed to attend follow up were excluded from the study.

\section{Data collection}


Demographic, obstetrical and general medical data were extracted from the patient's medical records. Preoperative examination was performed by a multidisciplinary team of urogynecologists and colorectal surgeons. Most patients had an endoanal ultrasound and a validated St. Marks faecal incontinence questionnaire, as well as Queensland pelvic floor questionnaire at their initial visit.

At the post-operative visit most women had a repeat St Marks score and some women a repeat endoanal ultrasound. Women who did not have sufficient follow up beyond 6 months were contacted via a phone interview which included a St Marks questionnaire. They were also asked if they would recommend the surgery to a friend and if they had any complications following the repair. The data was stored on the password protected and secured online University of Melbourne REDCap Database.

\section{Surgical Technique}

Surgical repair was performed by the five senior authors (PD, JK, LS, AD and AW). A midline incision was made on the lower posterior vaginal wall and perineum; the remnants of the external anal sphincter were identified and dissected out to 3' and 9'clock. An overlapping AS repair was performed using 2/0 PDS. A concomitant posterior colporrhaphy + /- perineorrhaphy was performed in all patients.

\section{Outcomes Measured}

Women were assessed at regular interval postoperatively and the results were tabulated at less than 6 months (short term) and greater than 6 months (long-term).

The Minimal important difference for the St Mark score has been evaluated as an improvement of more than 5 points by previous validation studies (11).

"Marked improvement" was defined as no or rare faecal incontinence (excluding flatal incontinence and faecal urgency). Quality of life improvement was established through the St Marks score item; 'how often does the incontinence impact (their) life' on a scale from 0-4 with 0 being never and 4 being on a daily basis.

In terms of assessing the presence of solid, liquid and fatal incontinence; patients were included that recorded a St mark score of more than "rare" (i.e. a score $>1$ ).

\section{Statistical analysis}

Information from the database was analysed in a de-identified manner using the REDcap data base system as well as SPSS (v25.0. Armonk, NY: IBM Corp). Variables were summarized as mean and SD, median and interquartile range (IQR) or count and percentage. Incontinence scores are presented as mean values. Paired nonparametric data were analysed using Wilcoxon signed rank sum test and independent categorical data will be analysed with the chi-squared test. In addition, scores of 0 or 1 on The St Marks Questionnaire with regard to solid, liquid, or flatal incontinence were analysed as "no incontinence" respectively, and pre-op and long-term follow-up for these variables were compared using McNemar's test. Values of $\mathrm{P}<0.05$ were considered statistically significant.

\section{Results}

107 women had AS repairs and were included in the study, 9 women had concurrent fistula repairs and were analysed as a separate group. 10 women were lost to follow up leaving 88 women for analysis.

\section{$<$ Fig1. Patient flow diagram $>$}

82 women of the total group of 88 women had follow-up of greater than 6 months. Median follow-up time was 57.5 months (IQR: 24.7-81.9). Demographic characteristics are presented in Table 1.

$<$ Table.1>

There was a significant reduction of the median St Marks score preoperatively of 17 compared to a postoperative score of $10(\mathrm{p}<0.001)$. 
$69.3 \%$ of women had a St marks score with a clinically meaningful improvement of more than 5 points. Out of these $46.5 \%$ of women had a marked improvement of their incontinence with $<1$ occurrence of faecal incontinence per month. $70 \%$ of patients would recommend the procedure to a friend (Table 2).

$<$ Table $2>$

Our patients' symptoms deteriorated with time when comparing short term follow up and Long term follow up. Changes in faecal urgency, faecal, liquid and flatal incontinence are shown in table 3.

$<$ Table3 $>$

Post-operative wound infection was reported by $45 \%$ of patients (40/88) with some form of perineal breakdown in $27 \%$ (24/88). Infection or breakdown did not seem to impact outcomes of the repair with significant improvement in the St mark score, similar to the scores of women in the overall group. These women were also as likely to recommend the procedure to a friend.

$<$ Table $4>$

16 patients had an endoanal ultrasound (EAUS) following their AS repair. Of these $68.7 \%$ had a persistent sphincter defect, 5 of 16 patients had a no defect. Patients with a persistent sphincter defect still demonstrated a significant improvement in the St marks score.

\section{$<$ Table $5>$}

Two of our women underwent a repeat sphincter repair. Both of these women later went on to having Sacral neuro modulation (SNS). Three other women went on to have SNS; one who gained significant improvement, the other two without significant change in the bowel function. Two women had an anal bulking agent injection following their sphincter repair without any improvement in their bowel function. Two women underwent a Fenton's repair for dyspareunia. One patient had wound breakdown and developed a rectovaginal fistula post operatively.

The 9 patients with concurrent AS repair and rectovaginal fistula all had a sphincter defect on pre-operative ultrasound. This group had a higher post-operative ST Marks score compare to the AS repair alone. Five of these 9 women had a significant improvement in their ST Marks score. All of the women with a concurrent fistula repair had successful fistula closure and had some form of wound infection and perineal breakdown as reported by the patient.

$<$ Table $6>$

\section{Discussion}

\section{Main Findings}

In spite of several preventive strategies, OASI is still a relatively common complication of vaginal delivery and associated with significant morbidity. The chance of anal incontinence following a primary repair is related to the degree of OASI (12)

Only $35 \%$ of our patients had a known primary OASI repair. Many of our patients were in the older age bracket and were not aware if they had a primary repair with their index delivery as this had not been well communicated to them, and some of our patients had occult OASI injuries.

Our study showed that the functional results of transvaginal AS repair have sustained satisfactory outcomes with almost $70 \%$ of patients having 5 points or more improvement of their St Mark score at 57 months. This outcome correlates with the fact that $70 \%$ of our women would recommend this procedure to a friend.

Our study indicated that $73 \%$ of women have persistent urgency post operatively, similar results of persistent urgency was also reported in a large Danish study with 220 months follow up (13). Ongoing urgency could be related to a persistent IAS defect. IAS defects are more difficult to identify and repair; particularly in a delayed setting, perhaps indicating that a sphincter repair should not be performed solely for faecal urgency. 
Overall rates of surgical complications after a sphincteroplasty range from $5 \%$ to $27 \%$. The most common adverse event after sphincteroplasty is wound infection, which occurs in $6-35 \%$ of cases. In our cohort we had a higher incidence of wound infection/perineal breakdown (45\%). This could be due to the fact most of our complications were patient reported, the rates of infection may thus be overestimated as many of our patients present with vaginal discharge as part of the healing process, that does not necessarily indicate a wound infection. Interestingly in our group of women with concurrent fistula repair all of the women reported symptoms of infection. Importantly the presence of wound infection or perineal breakdown did not change the outcomes in our study.

Perineal wound infection is uncommon after vaginal repair but when an AS repair is performed, the proximity to the anal canal dramatically increases the risk of infection and breakdown. Possible preventive measures for breakdown may be the use of drains, although this may cause sinus formation. Prophylactic antibiotics may reduce infection but there is no current evidence that prolonged antibiotic prophylaxis beyond the intra operative dose has any added benefit (14).

\section{Strengths and Limitations}

This is, to our knowledge, the largest study evaluating outcomes after transvaginal anal sphincter repair. It also boasts the longest median follow-up duration. The use of validated questionnaires, a uniform and specified sphincter repair technique, and analysis of results using the validated end point of meaningful clinical difference to define post op success improve the strength of the conclusions that are able to be drawn from this study.

The retrospective observational nature of this study is a key limitation. Recall bias with subsequent questionnaires and the subjective nature of patient reported outcomes another limitation.

\section{Interpretation of findings}

A large proportion of the existing literature on AS repairs relates to trans-perineal anterior sphincteroplasty often with no concurrent perineal body repair. The study demonstrates that, following a transvaginal repair, long-term functional results are better than previously reported in the literature. Gutierrez et al published on 182 patients undergoing an anterior sphincteroplasty without perineal body repair. $57 \%$ were still incontinent of solid stool at 10 year follow up (15). Barossa et al had 370 patients from a Danish registry with $54 \%$ still incontinent of solid stools at follow up (13). In our cohort we showed that only $26.8 \%$ of women were incontinent of solid stool at follow up. Furthermore, our study showed that $69.3 \%$ had a clinically significant improvement in their symptoms with $46.5 \%$ of patients showing a marked improvement in their incontinence. Whether this is causally related to the transvaginal route with a concurrent posterior repair is hard to determine in a retrospective observational study.

Perineal body thickness is a predictor of FI (16). It would make sense that reconstructing the perineal body with a perineorrhaphy at the time of surgery would improve continence score although further studies are needed to confirm this.

Briel et al compared complex repairs (with perineorrhaphy and restoring rectovaginal septum) vs simple repairs. This trial did not show any difference, the numbers were small and patients receiving simple repairs were done $>10$ yr prior to the complex repairs (17). Chase et al showed that all patients that had a levatorplasty at time of sphincter repair did well following sphincter repair, although this is based on only 6 patients (18).

We believe that a concomitant pelvic floor repair with the AS repair can improve results, as the pelvic floor and perineal body plays an important part in continence. Excessive vaginal narrowing from overtight levator sutures and introital stenosis resulting in dyspareunia in sexually active women should be avoided.

Successful anatomic repair of the defect would likely be a factor in predicting long-term functional outcomes; however, no series of long-term follow-up of patients with postoperative imaging exists (1). Engel et al compared US pre and post with a median follow up of 15 months. It showed that the postoperative squeeze 
pressure was increased, and the external sphincter was more frequently intact in those with a good outcome (19). In our case series, women with a persistent defect had a higher post-operative St Marks score compare to the women with no defect, but the numbers were small. Endoanal ultrasound may have the ability to identify those patients with poor results from an initial repair who may benefit from repeat repair (20).

An increasingly popular method to treat AI is with sacral neuromodulation. This has also been evaluated in women with sphincter defects. A prospective study on the efficiency of SNS for faecal incontinence following OASIS has shown that SNS can reduce weekly faecal incontinence, regardless of the extent of the sphincter defect (21). A Cochrane systematic review from 2015 showed favourable mid- and long-term positive outcomes for SNS. The review reported the success rates for SNS (based on at least $50 \%$ improvement in FI episodes per week) were $63 \%$, and $36 \%$ of participants achieved complete faecal continence. The quality of evidence was low and there was no consistent outcome reporting between studies making the analysis difficult (22). These figures may be reduced further when results are reanalysed using all available participants on an intention-to-treat basis. Furthermore, SNS has a high surgical revision rate of up to $32.5 \%$ for complications relating to the device such as pain and lead migration (23). A prospective comparative trial in women with sphincter defects would beneficial to help guide women and clinicians in the treatment of $\mathrm{AI}$ in the setting of sphincter defects.

\section{Conclusion}

Our data shows that the long-term success rate of transvaginal AS repair may be better than previously reported in the literature. Wound infection and perineal breakdown occurred in just under half of our cohort, but this did not seem to impact on the outcomes. Further comparative prospective studies and/or randomized control trials with consistent outcome reporting would add to the current gap in the literature.

\section{Acknowledgements/Funding}

No funding or sponsorship was received for this project. None of the authors have any financial, political or religious disclosure of interests.

Authors contributions

- Main Author; Frida Carswell.

- Supervising, planning and editing Professor Dwyer and Dr Lore Schierlitz.

- Creating of redcap data base, data analysis and editing Dr Madhu Bhamidipaty.

- Data collection and editing Dr Ariel Zilberlicht.

- Editing, Data collection and data provision; Dr Alex Wong and Dr Jamie Keck.

- Statistics and Editing; Dr James Alexander.

Ethics was approved by the Mercy Health Human Research Ethics Committee on the 10/12/2019 (more than low risk) approval number 2019-032.

\section{References}

1. Glasgow SC; Lowry AC. Long-term outcomes of anal sphincter repair for fecal incontinence: a systematic review. Diseases of the Colon \& Rectum. 2012 Apr; 55(4):482-90.

2. Johnson E, Carlsen E, Steen TB, Backer Hjorthaug JO, Eriksen MT, Johannessen HO. Short- and longterm results of secondary anterior sphincteroplasty in 33 patients with obstetric injury. Acta Obstet Gynecol Scand. 2010;89:1466 -1472.

3. Barisic G, Krivokapic Z, Markovic V. The role of overlapping sphincteroplasty in traumatic faecal incontinence. Acta Chir Iugosl. 2000;47:37-41.

4. Turel F, Langer S, Shek K, Dietz HP, Medium- to Long-term Follow-up of Obstetric Anal Sphincter Injury Dis Colon Rectum. 2019; 62: 348-356 
5 Malouf AJ, Norton CS, Engel AF, Nicholls RJ, Kamm MA. Long-term results of overlapping anterior anal-sphincter repair for obstetric trauma. Lancet. 2000;355:260-5.

5 Andrews V, Sultan AH, Thakar R, Jones PW. Occult anal sphincter injuries-myth or reality? BJOG. 2006 Feb;113(2):195-200.

6. Cook TA, Mortensen NJ. Management of faecal incontinence following obstetric injury. Br J Surg 1998; 85: 293-99.

7. Madoff RD. Surgical treatment options for fecal incontinence. Gastroenterology. 2004;126(1 Suppl 1):S48-54.

8 Kreydin E.I., Chaudhry Z.Q., Kazanjian K.K., Lin A.Y. Anal sphincteroplasty in the minimally invasive era: Assessment of national trends and complications. American Surgeon. January 2019; 85(1) 46-51

9. Young CJ, Mathur MN, Eyers AA, Solomon MJ. Successful overlapping anal sphincter repair: relationship to patient age, neuropathy, and colostomy formation. Dis Colon Rectum 1998; 41: 344-49.

10.Ctercteko GC, Fazio VW, Jagelman DG, Lavery IC, Weakley FL, Melia M. Anal sphincter repair: a report of 60 cases and review of the literature. Aust N Z J Surg 1998; 58: 703-10.

11. Richter HE, Jelovsek JE, Iyer P, Rogers RG, Meyer I, Newman DK et al ;Characteristics Associated With Clinically Important Treatment Responses in Women Undergoing Nonsurgical Therapy for Fecal Incontinence. Am J Gastroenterol. 2020 Jan;115(1):115-127.

12. Visscher AP, Lam TJ, Hart N, Felt-Bersma RJ. Fecal incontinence, sexual complaints, and anorectal function after third-degree obstetric anal sphincter injury (OASI): 5-year follow-up. Int Urogynecol J. 2014 May;25(5):607-13.

13. Barbosa M, Glavind-Kristensen M, Moller Soerensen M, Christensen P. Secondary sphincter repair for anal incontinence following obstetric sphincter injury: functional outcome and quality of life at 18 years of follow-up. Colorectal Dis 2020 Jan;22(1):71-79

14. Nelson RL, Gladman E, Barbateskovic M. Antimicrobial prophylaxis for colorectal surgery. Cochrane Database of Systematic Reviews 2014, Issue 5

15. B Gutierrez A, Madoff RD, Lowry AC, Parker SC, Buie, WD, Baxter NN. Long-term results of anterior sphincteroplasty. Dis Colon Rectum 2004;47(5):727-31.

16. Alhurry A.M.A.H., Akool M.A., Hosseini S.V., Khazraei H., Moosavi L., Pourahmad S. Does perineal body thickness affect fecal incontinence in multiparous patients? South African Journal of Obstetrics and Gynaecology. November 2018; 24 (2) 57-60.

17. Briel JW; de Boer LM; Hop WC; Schouten WR. Clinical outcome of anterior overlapping external anal sphincter repair with internal anal sphincter imbrication. Diseases of the Colon \& Rectum. 41(2):209-14, 1998 Feb.

18. Chase S; Mittal R; Jesudason MR; Nayak S; Perakath B. Anal sphincter repair for fecal incontinence: experience from a tertiary care centre. Indian Journal of Gastroenterology. 29(4):162-5, $2010 \mathrm{Jul}$.

19. Engel AF, Kamm MA, Sultan AH, Bartram CI, Nicholls RJ. Anterior anal sphincter repair in patients with obstetric trauma. Br J Surg 1994;81:1231-4.

19. Nielsen MB, Dammegaard L, Pedersen JF. Endosonographic assessment of the anal sphincter after surgical reconstruction. Dis Colon Rectum 1994;37(5):434-8.

21. Rydningen MB, Dehli T, Wilsgaard T et al. Sacral neuromodulation for faecal incontinence following obstetric sphincter injury - outcome of percutaneous nerve evaluation. Colorectal Dis. 2017; 19: 274- 82. 
22. Thaha MA, Abukar AA, Thin NN, Ramsanahie A, Knowles CH. Sacral nerve stimulation for faecal incontinence and constipation in adults. Cochrane Database of Systematic Reviews 2015, Issue 8

23. Schmidt RA1, Jonas U, Oleson KA, Janknegt RA, Hassouna MM, Siegel SW, van Kerrebroeck PE. Sacral nerve stimulation for treatment of refractory urinary urge incontinence. Sacral Nerve Stimulation Study Group. J Urol. 1999 Aug;162(2):352-7.

\section{Hosted file}

Fig1.docx available at https://authorea.com/users/441681/articles/542133-long-termfunctional-results-of-transvaginal-anal-sphincter-repair-for-faecal-incontinence-aretrospective-cohort-study

\section{Hosted file}

Table 1.docx available at https://authorea.com/users/441681/articles/542133-long-termfunctional-results-of-transvaginal-anal-sphincter-repair-for-faecal-incontinence-aretrospective-cohort-study

\section{Hosted file}

Table 2.docx available at https://authorea.com/users/441681/articles/542133-long-termfunctional-results-of-transvaginal-anal-sphincter-repair-for-faecal-incontinence-aretrospective-cohort-study

\section{Hosted file}

Table 3.docx available at https://authorea.com/users/441681/articles/542133-long-termfunctional-results-of-transvaginal-anal-sphincter-repair-for-faecal-incontinence-aretrospective-cohort-study

\section{Hosted file}

Table 4.docx available at https://authorea.com/users/441681/articles/542133-long-termfunctional-results-of-transvaginal-anal-sphincter-repair-for-faecal-incontinence-aretrospective-cohort-study

\section{Hosted file}

Table 5.docx available at https://authorea.com/users/441681/articles/542133-long-termfunctional-results-of-transvaginal-anal-sphincter-repair-for-faecal-incontinence-aretrospective-cohort-study

\section{Hosted file}

Table 6.docx available at https://authorea.com/users/441681/articles/542133-long-termfunctional-results-of-transvaginal-anal-sphincter-repair-for-faecal-incontinence-aretrospective-cohort-study 